\title{
Effect of Statin on Progression of Symptomatic Intracranial Atherosclerosis
}

\author{
Hye-Jin Kim, Eun-Kyung Kim, Sun U. Kwon, Jong S. Kim, Dong-Wha Kang
}

\begin{abstract}
Background: Symptomatic intracranial atherosclerosis (ICAS) is a dynamic disease that frequently progresses. Statins have been shown to have anti-atherosclerotic activity. We therefore investigated whether statins could prevent progression of ICAS. Methods: This retrospective cohort study assessed 55 patients with acute ischemic stroke and symptomatic ICAS in the middle cerebral or basilar arteries as shown on magnetic resonance angiography (MRA), with follow-up MRA performed more than 1 year after the index stroke. Change in ICAS was classified as progressive, regressive, or stable. Baseline clinical characteristics and risk factor control during follow-up were assessed, and laboratory tests were performed at the time of follow-up MRA. The statin group was defined as patients regularly treated with statins for more than $75 \%$ of the follow-up period; the remaining patients were defined as the non-statin group. Results: At a median follow-up time of 21.8 months (range, 11.8-66.1 months), the statin group consisted of 26 (47.3\%) patients and the non-statin group of 29 (52.7\%). During follow-up, 6 (10.9\%) patients progressed, $14(25.5 \%)$ regressed, and $35(63.6 \%)$ remained stable. Statin treatment was significantly associated with non-progression of ICAS ( $p=0.024)$. Two patients in the non-statin group had recurrent strokes. Border-zone infarcts were associated with progression of ICAS $(3 / 6,50 \%$; $p=0.007)$, whereas risk factors and inflammatory biomarkers were not related to progression. Conclusions: Treatment with statins may prevent progression of symptomatic ICAS. Prospective randomized controlled trials are required to confirm that statins protect against such progression.
\end{abstract}

RÉSUMÉ: Effet des statines sur la progression de l'athérosclérose intracrânienne symptomatique. Contexte : L'athérosclérose intracrânienne (ASIC) symptomatique est une maladie dynamique souvent progressive. Il a été démontré que les statines ont une activité antiathéroscléreuse. Nous avons donc analysé si les statines pouvaient prévenir la progression de l'ASIC. Méthode : Il s'agit d'une étude rétrospective de cohorte de 55 patients atteints d'un accident vasculaire cérébral aigu (AVCA) et d'ASIC symptomatique de l'artère cérébrale moyenne ou du tronc basilaire démontrée par angiographie par résonance magnétique (ARM) avec reprise de l'ARM au moins 1 an après l'AVCA. Le changement au niveau de l'ASIC était classifié comme une ASIC ayant progressé, régressé ou qui était stable. Les caractéristiques cliniques initiales de base et la réduction des facteurs de risque au cours du suivi ont été évaluées. Des épreuves de laboratoire ont été effectuées au moment de l'ARM de contrôle. Les patients qui avaient pris une statine régulièrement pendant plus de $75 \%$ de la période de suivi étaient inclus dans le groupe statine. Les autres patients étaient inclus dans le groupe sans statine. Résultats : Le temps médian écoulé entre l'AVCA et l'examen de suivi était de 21,8 mois (écart 11,8 à 66,1 mois). Le groupe statine incluait 26 patients $(47,3 \%)$ et le groupe sans statine 29 patients $(52,7 \%)$. Au cours du suivi, une progression a été observée chez 6 patients (10,9\%), une régression chez 14 patients $(25,5 \%)$ et 35 patients $(63,6 \%)$ sont demeurés stables. Le traitement par une statine était associé de façon significative à l'absence de progression de l'ASIC ( $=0,024)$. Deux patients du groupe sans statine ont subi d'autres AVC. Des infarctus dans la zone limite de l'AVC antérieur étaient associés à la progression de l'ASIC $(3 / 6,50 \% ; \mathrm{p}=0,007)$ alors que les facteurs de risque et les biomarqueurs de l'inflammation n'étaient par reliés à la progression. Conclusions : Le traitement par les statines peut prévenir la progression de l'ASIC. Notre observation que les statines protègent contre la progression de l'ASIC devra être confirmée par des essais cliniques prospectifs randomisés et contrôlés par placebo.

Can J Neurol Sci. 2012; 39: 801-806

Intracranial atherosclerosis (ICAS) is an important cause of ischemic stroke worldwide, particularly in Asian, African American, and Hispanic populations. ${ }^{1,2}$ The incidence of ischemic events in patients with symptomatic ICAS is almost four-fold greater than in patients with asymptomatic atherosclerosis. ${ }^{3}$ Moreover, patients with ICAS are at greater risk of recurrent stroke than are other stroke subtypes, as shown in population-based ${ }^{4}$, natural history ${ }^{5}$ and imaging ${ }^{6}$ studies.

Atherosclerosis is a dynamic disease that occasionally shows progression despite control of risk factors. ${ }^{7}$ Moreover, such progression may be an important surrogate marker for subsequent ischemic stroke, coronary heart disease, and death. . $^{-}$ 10 Therefore, not only treating the risk factors but also treating arteries based on plaque burden reduces stroke and cardiovascular events and it has been suggested as a new paradigm in the management of atherosclerosis. ${ }^{11-13}$ Prevention of ICAS progression may be an optimal strategy for secondary stroke prevention in such patients.

Statins have been shown to prevent progression or induce regression of atherosclerosis in the coronary and carotid arteries. ${ }^{14,15}$ Thus, statins may also protect against progression of

From the Department of Neurology, Asan Medical Center, University of Ulsan College of Medicine, Seoul, Republic of Korea.

Received January 4, 2012. Final Revisions Submitted May 15, 2012. Correspondence to: Dong-Wha Kang, Department of Neurology, Asan Medical Center, University of Ulsan College of Medicine, 88 Olympic-ro 43-gil, Songpa-gu, Seoul 138-736, Republic of Korea. E-mail: dwkang@amc.seoul.kr. 
ICAS. Little is known, however, about the effects of statin treatment on the natural history of ICAS. We therefore utilized serial magnetic resonance angiography (MRA) to determine whether statin treatment affected progression of symptomatic ICAS.

\section{Material AND MethodS}

\section{Recruitment of patients}

In this retrospective cohort study, consecutive patients who experienced acute ischemic stroke between November 2002 and October 2005 were recruited from the stroke center of the Asan Medical Center, Seoul, South Korea. Patients were included if they had (1) acute ischemic stroke as confirmed by diffusionweighted imaging (DWI), (2) symptomatic ICAS in the middle cerebral artery (MCA) or basilar artery (BA), defined as stenosis of the MCA or BA on MRA, and (3) acute ischemic lesions within the vascular territory of the stenosed artery that corresponded to the individual neurological deficit.

Patients were excluded if they had (1) intracranial arterial occlusion possibly caused by an embolism, (2) significant cardioembolic sources or tandem vascular lesions (i.e., internal carotid or vertebral stenosis), (3) non-atherosclerotic vasculopathy such as moyamoya disease or vasculitis, (4) malignancy, or (5) any medical condition that precluded magnetic resonance imaging. This study was approved by the Institutional Review Board of the Asan Medical Center. All patients or their legal guardians provided written informed consent at the time of long-term follow-up MRA.

Patient data collected at baseline included demographic factors; risk factors (hypertension, diabetes mellitus, coronary heart disease, hypercholesterolemia and current [current or quit for < six months] cigarette smoking); and stroke severity, as measured by the National Institutes of Health Stroke Scale (NIHSS), at both admission and at discharge. Hypercholesterolemia was defined as prescription of cholesterolreducing agents, an overnight fasting total cholesterol concentration $\geq 200 \mathrm{mg} / \mathrm{dL}$, or a low-density lipoprotein cholesterol concentration $\geq 130 \mathrm{mg} / \mathrm{dL}$.

\section{Statin treatment}

In line with The National Cholesterol Education Program Adult Treatment Panel III (NCEP ATP III) guidelines, acute stroke patients in our center with hypercholesterolemia at baseline (low-density lipoprotein cholesterol $\geq 130 \mathrm{mg} / \mathrm{dL}$ ) were treated with statins, with the type and dosage being decided by each attending physician. Compliance with statin treatment was evaluated by chart review and interview at the time of long-term follow-up MRA. Patients who regularly remained on statins for $>75 \%$ of follow-up time were categorized as the statin group; those who did not were classified as the non-statin group.

\section{Magnetic Resonance Imaging assessment}

Magnetic resonance imaging (MRI) examinations were performed using a 1.5 Tesla MR imaging unit (Signa, GE Medical Systems) with echo-planar capabilities. Threedimensional time-of-flight intracranial MRAs (TOF-MRAs) were performed using a repetition time (TR) of 25 milliseconds (msec) and a echo time (TE) of $2 \mathrm{msec}$, and three-dimensional
(3D) contrast-enhanced extracranial MRAs from the aortic arch were obtained after an intravenous bolus injection of $20 \mathrm{~mL}$ (3$4 \mathrm{~mL} / \mathrm{sec}$ ) gadopentetate dimeglumine.

Our acute stroke protocol requires patients to undergo two MRA evaluations during the acute stage, once within 24 hours of onset, and next five days after the index stroke. It has been reported that the spontaneous recanalization of embolic occlusion usually occurs within 24 hours $^{16}$ and residual significant stenosis on follow-up imaging can be considered as ICAS. ${ }^{17}$ Accordingly, we enrolled the patients only if they had evidence of luminal stenosis on the five day follow-up MRA. Long-term follow-up 3D TOF-MRA was performed more than one year after the index stroke. The MRA findings were independently reviewed by an investigator (H-JK) blinded to clinical and other MRI data (except for the side on which the lesion had occurred). For determining stenosis degree in ambiguous cases, final decision was made when two experienced stroke neurologists (H-JK and D-WK) achieved consensus. The degree of ICAS was semi-quantitatively classified into five grades: normal, mild $(<50 \%$ signal reduction), moderate ( $\geq 50 \%$ signal reduction), severe (focal signal loss with the presence of a distal flow signal), and occluded. ${ }^{6}$ Change in the degree of ICAS was classified as progression (worsening of stenosis by $\geq 1$ grade on follow-up MRA), regression (improvement in stenosis by $\geq 1$ grade), or stable. ${ }^{18}$

\section{Patient follow-up}

Laboratory tests (complete blood count; blood chemistry; lipid profile; and measurements of $\mathrm{C}$-reactive protein, lipoprotein (a), apolipoprotein A1 and B, and electrolytes) were performed; and height, body weight, waist circumference, and functional outcome measured by the modified Rankin Scale (mRS) were determined at the time of follow-up MRA. Risk factor control, type and dosage of medications, and drug compliance during follow-up were evaluated. In addition, each patient and/or caregiver was asked whether clinical events had occurred after discharge from the index stroke admission. Such questions were posed by an independent investigator (E-KK) blinded to clinical and imaging information.

\section{Data analysis}

Descriptive results of continuous variables are expressed as mean \pm standard deviation (SD). Demographics and vascular risk factors at baseline were compared between the statin and non-statin groups, with continuous variables evaluated using Student's t-test or the Mann-Whitney $U$ test, and categorical variables compared employing the $\chi^{2}$ or Fisher's exact tests, as appropriate. We also compared change in ICAS, clinical recurrence, and laboratory results at the time of follow-up MRA between the two groups. A two-tailed $p$ value $<0.05$ was defined as statistically significant. All statistical analyses were performed using SPSS for Windows (version 14.0; SPSS Inc., Chicago. IL).

\section{RESULTS}

Review of the medical records of the stroke center at the Asan Medical Center screened 698 patients who had intracranial large 
artery atherosclerosis confirmed by 5-day MRA over the 3-year study period. Of these, 392 patients who had symptomatic ICAS in the MCA or BA were identified. An additional 90 patients were excluded: 45 with thrombolytic therapy, 45 with interventional recanlization procedure. Among the remaining 302 patients, 9 patients died in the hospital, 150 patients transferred to other hospitals, and 71 patients were excluded due to poor outcomes (mRS 4-5 or comorbidity with other medical diseases). Therefore, 72 patients were eligible and agreed to participate in this study and underwent long-term follow-up MRA. Among them, 17 patients with occlusions on 5-day MRA were excluded because of a ceiling effect. Finally, 55 patients were eligible: 29 (52.7\%) were men and 26 (47.3\%) women; their median age was 68 years (mean \pm SD, $66 \pm 10$ years; range, 39-87 years). The median time from stroke onset to follow-up MRA was 21.8 months (range 11.8-66.1 months). Twenty-nine patients received statin medications, but three were classified into the non-statin group because of poor compliance. Thus, the statin group contained $26(47.3 \%)$ patients and the non-statin group $29(52.7 \%)$. Of the patients in the statin group, 11 were treated with atorvastatin (10-20 mg/day), 9 with pravastatin (10$20 \mathrm{mg}$ /day), 5 with simvastatin $(20 \mathrm{mg} /$ day $)$, and 1 with rosuvastatin $(10 \mathrm{mg} /$ day $)$. In the comparison between included and excluded patients, excluded patients had severe stroke symptoms and lower rate of prescription of antiplatelet agents. However, demographics and statin therapy were not different.

\section{Baseline characteristics of the statin and non-statin groups}

We observed no differences in demographic features, risk factors, or laboratory or imaging characteristics between the statin and non-statin groups, except that hypercholesterolemia was more frequent in the statin than in the non-statin group (5 vs. $0 ; \mathrm{p}=0.019$; Table 1). The two groups did not differ in the number of stenotic vessels or the degree of ICAS, in use of anticoagulation or antiplatelet therapy for prevention of recurrent stroke, or in the number of antiplatelet agents prescribed.

\section{Follow-up findings in the statin and non-statin groups}

On follow-up MRA, 6 patients $(10.9 \%)$ showed progression and $14(25.5 \%)$ showed regression of index ICAS lesions, whereas the remaining $35(63.6 \%)$ were stable. Statin treatment was significantly associated with non-progression of ICAS $(\mathrm{p}=0.024)$. Prescription of any statin medication, regardless of compliance, was also significantly related to non-progression $(\mathrm{p}=0.008)$. Recurrent ischemic events occurred in two patients in the non-statin group, and both were attributed to pre-existing ICAS. In contrast, no patient in the statin group had a recurrent stroke. Lipid profile indices were significantly reduced in the statin group compared with the non-statin group, whereas other inflammatory biomarkers did not differ between the two groups (Table 2).
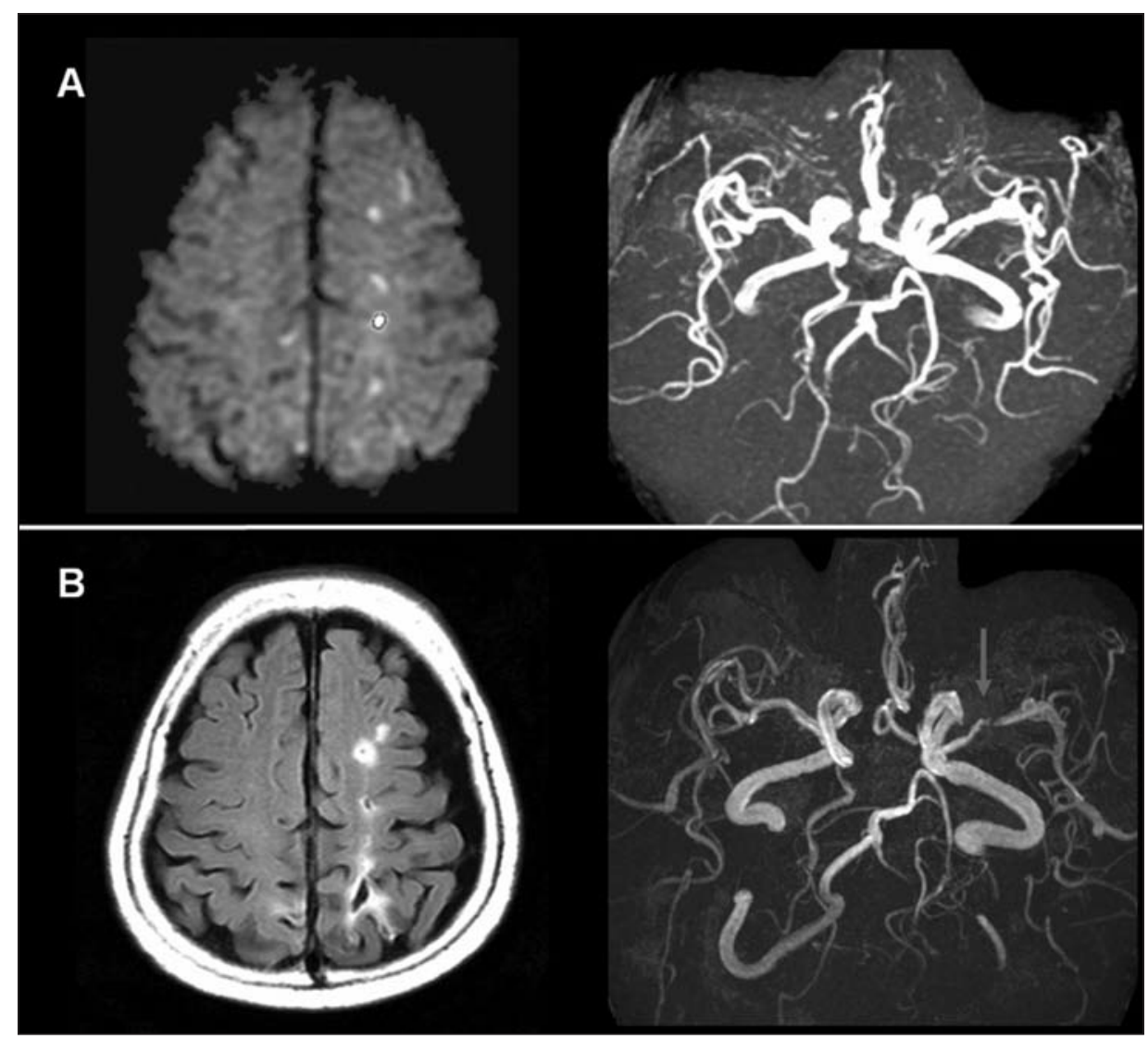

Figure: An 80-year-old woman presented with global aphasia and right hemiparesis. She had no embolic source; thus no high-risk cardioembolism or carotid artery disease, and no history of hemodynamic insufficiency. Initial DWI showed a border-zone infarct with mild M1 stenosis (A). After 27.5 months, follow-up MRA showed that M1 stenosis had progressed (B). Arrows indicate the sites of $M C A$ stenosis. 
Table 1: Baseline characteristics of the statin and non-statin groups

\begin{tabular}{|c|c|c|}
\hline & $\begin{array}{c}\text { Statin group } \\
(n=26)\end{array}$ & $\begin{array}{c}\text { Non-statin group } \\
(\mathbf{n}=29)\end{array}$ \\
\hline \multicolumn{3}{|l|}{ Demographics } \\
\hline Age (years) & $68(44-87)$ & $67(39-82)$ \\
\hline Gender (male) & $11(42.3 \%)$ & $18(62.1 \%)$ \\
\hline \multicolumn{3}{|l|}{ Risk factors } \\
\hline Hypertension & $24(92.3 \%)$ & $23(79.3 \%)$ \\
\hline Diabetes mellitus & $7(26.9 \%)$ & $6(20.7 \%)$ \\
\hline Coronary heart disease & $4(15.4 \%)$ & $2(6.9 \%)$ \\
\hline Hypercholesterolemia & $5(10.2 \%)$ & $0(0 \%)$ \\
\hline Current smoking & $8(30.8 \%)$ & $15(51.7 \%)$ \\
\hline Metabolic syndrome & $15(57.7 \%)$ & $12(41.4 \%)$ \\
\hline \multicolumn{3}{|l|}{ Laboratory data at admission } \\
\hline 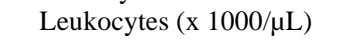 & $7.6(4.7-12.0)$ & $7.5(5.4-16.4)$ \\
\hline Total cholesterol (mg/dL) & $196.0(123.0-255.0)$ & $156.0(120.0-221.0)$ \\
\hline $\mathrm{LDL}(\mathrm{mg} / \mathrm{dL})$ & $124.0(55.0-198.0)$ & $86.0(58.0-159.0)$ \\
\hline Triglyceride (mg/dL) & $136.5(45.0-266.0)$ & $104.0(38.0-238.0)$ \\
\hline HDL (mg/dL) & $44.0(23.0-63.0)$ & $47.8(28.0-69.0)$ \\
\hline Non-HDL (mg/dL) & $141.5(65.0-211.0)$ & $104.0(70.0-167.0)$ \\
\hline C-reactive protein $(\mathrm{mg} / \mathrm{dL})$ & $0.28(0.1-2.67)$ & $0.25(0.01-1.1)$ \\
\hline \multicolumn{3}{|l|}{ Stenotic vessel } \\
\hline $\operatorname{MCA}(n=46)$ & $21(80.8 \%)$ & $25(86.2 \%)$ \\
\hline $\mathrm{BA}(\mathrm{n}=9)$ & $5(19.2 \%)$ & $4(13.8 \%)$ \\
\hline \multicolumn{3}{|l|}{ Initial MRA stenosis } \\
\hline Mild (n=17) & $7(26.9 \%)$ & $10(34.5 \%)$ \\
\hline Moderate $(n=24)$ & $12(46.2 \%)$ & $12(41.4 \%)$ \\
\hline Severe $(n=14)$ & $7(26.9 \%)$ & $7(24.1 \%)$ \\
\hline NIHSS score on admission & $4.5(1-15)$ & $5(1-14)$ \\
\hline
\end{tabular}

Results expressed as number (column \%), median (range). LDL = low density lipoprotein, HDL = high density lipoprotein, $\mathrm{MCA}=$ middle cerebral artery, BA = basilar artery, NIHSS = National institutes of Health Stroke Scale.

\section{Comparison between the progression and non-progression groups}

When we divided patients into those with and without ICAS progression, we observed no differences in patient demographics, risk factors, inflammatory biomarkers during the follow-up period. However, the MRI lesion patterns differed significantly. Small perforator infarcts were more frequently observed in the non-progression group $(23 / 49,46.9 \%$; $\mathrm{p}=0.035)$, whereas single or multiple border-zone infarcts were more often present in the progression group $(3 / 6,50 \%$; $\mathrm{p}=0.007)$.

\section{DisCUSSION}

In this observational study evaluating the effects of statins on the natural history of symptomatic ICAS, we found that statin treatment may halt ICAS progression. These findings provide evidence of the beneficial effects of statins on ICAS progression and are in good agreement with the results of studies showing the effects of statins on coronary and carotid atherosclerosis. ${ }^{14,15}$

Although statins have been shown to exert beneficial effects in stroke patients, as evidenced by a reduction in infarct size and an improvement in cerebral blood flow in animal models ${ }^{19}$, and prevention of recurrent stroke in humans ${ }^{20,21}$, the effects of statins on ICAS progression have not been well studied. In a recent Chinese report, statin treatment did not show beneficial effects in patients with asymptomatic ICAS. ${ }^{22}$ In contrast, another study found that statin treatment resulted in regression of symptomatic ICAS in more than $50 \%$ of patients, but this group was not compared with a non-statin- treated group of patients. ${ }^{23}$ Previous observational studies on the natural history of ICAS have shown progression in $9-32.5 \%$ of patients and regression in $7.5-29 \% .^{7,8,10,18}$ Moreover, the annual rate of new ischemic stroke or transient ischemic attack in the territory of the stenosed artery was found to be $15-38.2 \% .^{5,24}$ Recently, the rate of recurrent ischemic stroke or death for the patients receiving intensive medical therapy was shown to be much lower $(12.2 \%)$ than expected ${ }^{25}$ and it was suggested that well-controlled risk factors including lipid level or blood pressures might contribute to good outcomes. In the same context, the rate of progression and clinical recurrence was as low as $10.9 \%$ and $6.9 \%$. Therefore, it is possible that statin therapy could reduce the risk of subsequent stroke in symptomatic ICAS.

The mechanism underlying the protective effects of statins may be related to the anti-atherogenic properties of the drugs. Despite the fact that our statin group had more frequent hypercholesterolemia and higher lipid profiles than non-statin group, we found that statin treatment had beneficial effects on the progress of symptomatic ICAS. Thus the protective effects of statins may be underestimated in this study, because elevated 
Table 2: Follow-up laboratory and imaging findings in the statin and non-statin groups

\begin{tabular}{|c|c|c|c|}
\hline & $\begin{array}{c}\begin{array}{c}\text { Statin group } \\
(\mathrm{n}=\mathbf{2 6})\end{array} \\
\end{array}$ & $\begin{array}{c}\text { Non-statin group } \\
(\mathrm{n}=\mathbf{2 9})\end{array}$ & $\mathbf{p}$ \\
\hline \multicolumn{4}{|l|}{$\begin{array}{l}\text { Laboratory findings } \\
\text { at follow-up }\end{array}$} \\
\hline 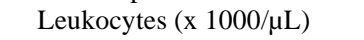 & $6.8(3.4-10.1)$ & $5.85(2.5-11.5)$ & 0.261 \\
\hline Total cholesterol (mg/dL) & $159.0(119.0-227.0)$ & $178.0(139.0-238.0)$ & 0.001 \\
\hline $\mathrm{LDL}(\mathrm{mg} / \mathrm{dL})$ & $99.0(48.0-143.0)$ & $120.0(78.0-186.0)$ & $<0.001$ \\
\hline Triglyceride $(\mathrm{mg} / \mathrm{dL})$ & $112.0(53.0-464.0)$ & $138.0(39.0-568.0)$ & 0.386 \\
\hline $\operatorname{HDL}(\mathrm{mg} / \mathrm{dL})$ & $53.0(38.0-86.0)$ & $51.5(35.0-82.0)$ & 0.555 \\
\hline Non-HDL (mg/dL) & $109.0(51.0-187.0)$ & $129.0(81.0-203.0)$ & $<0.001$ \\
\hline Apolipoprotein A1 (mg/dL) & $143.6(106.6-203.1)$ & $136.6(108.0-190.1)$ & 0.256 \\
\hline Apolipoprotein B (mg/dL) & $69.5(32.7-120.4)$ & $85.1(51.7-128.9)$ & 0.001 \\
\hline Apolipoprotein B/A1 ratio & $0.47(0.2-0.89)$ & $0.63(0.34-1.0)$ & 0.002 \\
\hline Lipoprotein (a) (mg/dL) & $20.9(<5.0-171.8)$ & $27.7(<5.0-114.3)$ & 0.390 \\
\hline C-reactive protein $(\mathrm{mg} / \mathrm{dL})$ & $0.12(0.03-1.11)$ & $0.09(0.03-2.07)$ & 0.897 \\
\hline Progression of stenosis $(n=6)$ & $0(0 \%)$ & $6(20.7 \%)$ & 0.024 \\
\hline Ischemic recurrence $(n=2)$ & $0(0 \%)$ & $2(6.9 \%)$ & 0.492 \\
\hline
\end{tabular}

Results expressed as number (column \%), median (range). LDL = low-density lipoprotein, HDL = highdensity lipoprotein, MRA = magnetic resonance angiography.

cholesterol levels in symptomatic ICAS patients have been associated with an increased risk of stroke. ${ }^{26}$ In terms of antiinflammatory effects of statin, we found no correlation of Creactive protein with statin treatment or ICAS progression, although ICAS progression was related to $\mathrm{C}$-reactive protein concentration in a previous report. ${ }^{27}$

Baseline DWI infarct patterns, particularly border-zone infarcts, have been associated with ICAS progression. Borderzone infarcts are related to early neurological deterioration, development of new ischemic lesions, and clinical recurrence in ICAS patients. ${ }^{28,29}$ Thus, border-zone infarcts may indirectly reflect the presence of unfavorable ICAS, such as unstable plaques.

Our study had several limitations. First, the work was a retrospective, small sample sized and non-randomized study. Moreover, not all patients with ICAS were enrolled, resulting in selection bias; patients with severe stroke could not be followedup, which might underestimate the progression of ICAS or incidence of recurrent stroke. In addition, the time point for follow-up MRA is variable (11.8 66.1 months) among patients owing to retrospectively collected data. Second, the drug and its dosage were chosen by each physician's decision and not by standardized protocol, thus introducing bias. Third, we used only MRA to assess progression of ICAS. Additional modalities such as catheter angiography or transcranial Doppler scanning would strengthen the reliability of our results. However, MRA is a noninvasive and well-validated method ${ }^{30}$ and the semi-quantitatively MRA grading system showed good correlation with catheter angiography. ${ }^{31}$ In addition, we used the upgraded criteria which were applied to previous clinical trials. ${ }^{18,32}$

In conclusion, statin treatment may have favorable effects on the progression of symptomatic ICAS. Further prospective randomized controlled trials are required to confirm our observations.

\section{ACKNOWLEDGEMENT}

This study was supported by a grant (2011-0538) from the Asan Medical Center, Seoul, Republic of Korea.

\section{REFERENCES}

1. Gorelick PB, Han J, Huang Y, Wong KS. Epidemiology. In: Jong S. Kim, Louis R Caplan, K.S. Lawrence Wong, editors. Intracranial Atherosclerosis. Oxford: Wiley-Blackwell; 2008. p. 33-44.

2. Gorelick PB, Wong KS, Bae HJ, Pandey DK. Large artery intracranial occlusive disease: a large worldwide burden but a relatively neglected frontier. Stroke. 2008;39(8):2396-9.

3. Kern R, Steinke W, Daffertshofer M, Prager R, Hennerici M. Stroke recurrences in patients with symptomatic vs asymptomatic middle cerebral artery disease. Neurology. 2005;65(6):859-64.

4. Lovett JK, Coull AJ, Rothwell PM. Early risk of recurrence by subtype of ischemic stroke in population-based incidence studies. Neurology. 2004;62(4):569-73.

5. Mazighi M, Tanasescu R, Ducrocq X, et al. Prospective study of symptomatic atherothrombotic intracranial stenoses: the GESICA study. Neurology. 2006;66(8):1187-91.

6. Kang DW, Kwon SU, Yoo SH, et al. Early recurrent ischemic lesions on diffusion-weighted imaging in symptomatic intracranial atherosclerosis. Arch Neurol. 2007;64(1):50-4.

7. Akins PT, Pilgram TK, Cross DT, 3rd, Moran CJ. Natural history of stenosis from intracranial atherosclerosis by serial angiography. Stroke. 1998;29(2):433-8.

8. Wong KS, Li H, Lam WW, Chan YL, Kay R. Progression of middle cerebral artery occlusive disease and its relationship with further vascular events after stroke. Stroke. 2002;33(2):532-6.

9. Thijs VN, Albers GW. Symptomatic intracranial atherosclerosis: outcome of patients who fail antithrombotic therapy. Neurology. 2000;55(4):490-7.

10. Arenillas JF, Molina CA, Montaner J, et al. Progression and clinical recurrence of symptomatic middle cerebral artery stenosis: a long-term follow-up transcranial Doppler ultrasound study. Stroke. 2001;32(12):2898-904.

11. Spence JD, Hackam DG. Treating arteries instead of risk factors: a paradigm change in management of atherosclerosis. Stroke. 2010;41(6):1193-9. 
12. Spence JD, Coates V, Li H, et al. Effects of intensive medical therapy on microemboli and cardiovascular risk in asymptomatic carotid stenosis. Arch Neurol. 2010;67(2):180-6.

13. Spence JD. Carotid plaque measurement is superior to IMT. Atherosclerosis. 2012;220(1):34-5.

14. Nissen SE, Nicholls SJ, Sipahi I, et al. Effect of very high-intensity statin therapy on regression of coronary atherosclerosis: the ASTEROID trial. JAMA. 2006;295(13):1556-65.

15. Crouse JR, 3rd, Raichlen JS, Riley WA, et al. Effect of rosuvastatin on progression of carotid intima-media thickness in low-risk individuals with subclinical atherosclerosis: the METEOR Trial. JAMA. 2007;297(12):1344-53.

16. Molina CA, Montaner J, Abilleira S, et al. Timing of spontaneous recanalization and risk of hemorrhagic transformation in acute cardioembolic stroke. Stroke. 2001;32(5):1079-84.

17. Cho AH, Kwon SU, Kim JS, Kang DW. Evaluation of early dynamic changes of intracranial arterial occlusion is useful for stroke etiology diagnosis. J Neurol Sci. 2012;312(1-2):127-30.

18. Kwon SU, Cho YJ, Koo JS, et al. Cilostazol prevents the progression of the symptomatic intracranial arterial stenosis: the multicenter double-blind placebo-controlled trial of cilostazol in symptomatic intracranial arterial stenosis. Stroke. 2005;36(4): 782-6.

19. Endres M, Laufs U, Huang Z, et al. Stroke protection by 3-hydroxy3-methylglutaryl (HMG)-CoA reductase inhibitors mediated by endothelial nitric oxide synthase. Proc Natl Acad Sci USA. 1998;95(15):8880-5

20. Amarenco P, Bogousslavsky J, Callahan A, 3rd, et al. High-dose atorvastatin after stroke or transient ischemic attack. N Engl J Med. 2006;355(6):549-59.

21. Anand SS. Quantifying effect of statins on low density lipoprotein cholesterol, ischaemic heart disease, and stroke: systematic review and meta-analysis. Law MR, Wald NJ, Rudnicka AR. BMJ 2003; 326: 1407-8.

22. Mok VC, Lam WW, Chen XY, et al. Statins for asymptomatic middle cerebral artery stenosis: the regression of cerebral artery stenosis study. Cerebrovasc Dis. 2009;28(1):18-25.
23. Tan TY, Kuo YL, Lin WC, Chen TY. Effect of lipid-lowering therapy on the progression of intracranial arterial stenosis. J Neurol. 2009;256(2):187-93.

24. Chimowitz MI, Lynn MJ, Howlett-Smith H, et al. Comparison of warfarin and aspirin for symptomatic intracranial arterial stenosis. N Engl J Med. 2005;352(13):1305-16.

25. Chimowitz MI, Lynn MJ, Derdeyn CP, et al. Stenting versus aggressive medical therapy for intracranial arterial stenosis. $\mathrm{N}$ Engl J Med. 2011;365(11):993-1003.

26. Chaturvedi S, Turan TN, Lynn MJ, et al. Risk factor status and vascular events in patients with symptomatic intracranial stenosis. Neurology. 2007;69(22):2063-8.

27. Arenillas JF, Alvarez-Sabin J, Molina CA, et al. Progression of symptomatic intracranial large artery atherosclerosis is associated with a proinflammatory state and impaired fibrinolysis. Stroke. 2008;39(5):1456-63.

28. Kim JT, Kim HJ, Yoo SH, et al. MRI findings may predict early neurologic deterioration in acute minor stroke or transient ischemic attack due to intracranial atherosclerosis. Eur Neurol. 2010;64(2):95-100.

29. Bang OY, Lee PH, Heo KG, Joo US, Yoon SR, Kim SY. Specific DWI lesion patterns predict prognosis after acute ischaemic stroke within the MCA territory. J Neurol Neurosurg Psychiatry. 2005;76(9):1222-8.

30. Choi CG, Lee DH, Lee JH, et al. Detection of intracranial atherosclerotic steno-occlusive disease with 3D time-of-flight magnetic resonance angiography with sensitivity encoding at 3T. AJNR Am J Neuroradiol. 2007;28(3):439-46.

31. Rother J, Schwartz A, Rautenberg W, Hennerici M. Middle cerebral artery stenoses: assessment by magnetic resonance angiography and transcranial doppler ultrasound. Cerebrovasc Dis. 1994;4: 273-9.

32. Kwon SU, Hong KS, Kang DW, et al. Efficacy and safety of combination antiplatelet therapies in patients with symptomatic intracranial atherosclerotic stenosis. Stroke. 2011;42(10): 2883-90. 